\title{
Saberes que configuran trayectorias migratorias: narraciones de mujeres colombianas migrantes en Chile
}

\author{
Knowledge that shapes Migratory Trajectories: \\ Narratives of Colombian Migrant Women in Chile
}

\author{
Sylvia Contreras-Salinas (D) https://orcid.org/0000-0003-2297-2399 \\ Universidad de Santiago de Chile, Chilesylvia.contreras.s@usach.cl \\ Cristina Bambague-Ruiz (D) https://orcid.org/0000-0002-9875-0330 \\ Universidad Central de Chile, Chile, cristinabrgbrg@gmail.com \\ Yolima Barrera-Ruiz (D) https://orcid.org/0000-0002-0661-7699 \\ Universidad Central de Chile, Chile, /yolybruiz@hotmail.com
}

\begin{abstract}
The objective of this research is to disclose the knowledge that six Colombian professional women display in their migratory trajectories in Chile, particularly in upbringing process. From the narrative approach, a case study method was resorted to through interviews. Among the results obtained, it is revealed that the legitimacy of migrant women is conditional on fulfilling their role as workers, with merit and effort gaining strength. Likewise, knowledge that resists the colonial matrix is recognized, displaying diverse strategies recreated in the processes of upbringing, considering them necessary for the welfare of the children. It is concluded that the discovery of knowledge triggers a multiplicity of experiences that put tension in the prevailing forms of neo-capitalism, warn about the subtle disciplinary practices and reveal resistance practices, contributing to scientific thinking with the possibility of distancing oneself from a binary and hierarchical ideology regarding the local and universal.
\end{abstract}

Key words: migration, narratives, knowledge, women, experience.

Resumen: El objetivo de esta investigación es desvelar los saberes que despliegan seis mujeres profesionales colombianas en sus trayectorias migratorias en Chile, en particular en los procesos de crianza. Desde el enfoque narrativo, se utilizó el método de estudio de casos, mediante entrevistas. Entre los resultados obtenidos, se releva que la legitimidad de las mujeres migrantes está condicionada a cumplir su rol de trabajadoras, cobrando fuerza el mérito y el esfuerzo. Asimismo, se reconocen saberes que resisten la matriz colonial, desplegando diversas estrategias recreadas en los procesos de crianza, por

Recepción:

$22 / 01 / 2018$

Aprobación:

02/07/2018 considerarlos necesarios para el bienestar de los hijos. Se concluye que el desvelo de saberes detona una multiplicidad de experiencias, las cuales ponen en tensión las formas imperantes del neocapitalismo, alertan sobre las sutiles prácticas de disciplinamiento y relevan prácticas de resistencia, contribuyendo al pensamiento científico con la posibilidad de distanciarse de una ideología binaria y jerárquica, respecto a lo local y universal.

Palabras clave: migración, narraciones, saberes, mujeres, experiencia. 


\section{Introducción $^{1}$}

\section{Narraciones y saberes}

La migración es un fenómeno que interpela a las ciencias sociales, puntualmente en sostener una permanente vigilancia epistemológica respecto a qué y cómo se producen las categorías que permiten comprender la conformación de dicho fenómeno en contradicciones, fragmentaciones, presencias y ausencias (Sayad, 2011). A todo esto, se suman las paradojas, que obligan al migrante a reconocer, reconstruir y explotar la diferencia, a través de la resistencia y su afirmación como sujeto en proceso (Alarcón, 1997). Resistencia que en una matriz colonial radica en activar prácticas, maneras de ser y de pensar que para cada cual son constitutivas, oponiéndose a una reducción deshumanizante frente a lo cual se está forzando y resistiendo a ser sujetos permitidos (Lugones, 2008 y 2011). Esto, en un contexto donde la migración se configura en una funcionalidad que declara la apertura en los países de acogida a los migrantes, pero que en realidad acciona dispositivos concretos para restringir sus derechos (Tijoux, 2016). En este proceso se ha ido perpetuando la configuración histórica de imaginarios y estereotipos en torno a los empleos ejercidos por ciertos hombres y mujeres; es decir, un trabajo racializado que opera mediante marcaciones, ubicando a determinados grupos en lugares específicos de la estructura social (Baeza, 2015).

Este es, quizás, el motivo por el cual en las últimas décadas se aprecia una selectividad sostenida por género, atribuible a la demanda global de mano de obra (Massey et al., 1994; Loebach y Korinek, 2012). Se observa un proceso de feminización de las migraciones, asociado con la generación de fuentes de empleo en torno a la labor del cuidado y la crianza, donde las mujeres migrantes construyen trayectorias de subordinación y vulnerabilidad, además de permitir la perpetuación del sistema capitalista y patriarcal, vinculado con la dinámica de poder colonial alrededor de los puestos de trabajo (Olivos y Sandoval, 2015). Se corrobora la concepción de que la migración refuerza las jerarquías coloniales (Padilla y Cuberos-Gallardo, 2016). Un sistema colonial que impone una jerarquía dicotómica entre lo humano y lo no humano o entre los nacionales y los migrantes, donde el sujeto "autóctono" se convierte en sujeto/agente referente (Lugones, 2011, 2008).

1 El presente artículo fue realizado en el marco del proyecto Fondecyt núm. 11150362 titulado: "Trayectorias educativas y saberes socialmente producidos que despliegan mujeres migrantes en los procesos de inclusión en la Región Metropolitana de Chile". Agradecimientos a Fondecyt-Chile. Además, se agradece el apoyo de la Dirección de Investigación Científica y Tecnológica (DICYT), de la Universidad de Santiago de Chile. 
En suma, la migración refiere en especial a las herencias del problema colonial, vigente en la constitución y formación de los Estados nacionales en América Latina; la lógica colonial continúa funcionando, rearticulada por la presencia de formas de explotación al interior de los países, al ser lo colonial una constante en la historia de las sociedades latinoamericanas, cuyas desigualdades remiten a un horizonte colonial profundo (Rivera-Cusicanqui, 1993; Baeza, 2015). Claramente, el peso colonial es un fenómeno en permanente reformulación, en particular en los procesos migratorios, lo cual es un elemento clave para comprender el racismo, que se conforma en la paradoja del universalismo/particularismo, donde prima la idea de "que las culturas históricas de la humanidad se dividen en dos grandes clases: las que se suponen universalistas, progresivas y las irremediablemente particularistas, primitivas" (Wallerstein y Balibar, 1991).

En este marco, solo resta revelar maneras más humanas de abordar el fenómeno de la migración, motivo por el cual este artículo reivindica la pertinencia de la narración y los saberes. En cuanto a la narración, cabe mencionar que esta se asocia con una determinada comprensión de la realidad, que ofrece, entre otras cosas, la posibilidad de crítica a los discursos hegemónicos, mediante experiencias corporeizadas específicas de subjetividad (Grollmus y Tarrés, 2015), sometidas a un ethos del trabajo cuya base es la explotación que se presenta bajo diferentes caras, "en que el racismo no se atreve a salir sin maquillarse, pues él mismo se niega" (Fanon, 1956: 43).

Conjuntamente, se configuran narrativas capaces de negociar las diferencias de significado e interpretación con sus respectivos horizontes abiertos (Gadamer, 1998). Por tanto, dan cuenta del enojo, del ya está bueno de guardarse y que se tiene que ir saliendo, de memorias no apaciguadas del colonialismo (Lugones, 2008). En otras palabras, la narración permite una acción mimética, "ir más allá de sí mismo [lenguaje], y especialmente de la dimensión ontológica-referencial”, lo cual en su interpretación buscará "desplegar el mundo de su referencia en virtud de su disposición" (Ricoeur, 2001: 298). Es decir, en la narración se entreteje la vida de quienes habitan simultáneamente diversos mundos, atrapados entre normas y prácticas culturales diferentes; aquellos que sufren una guerra interna o una colisión cultural (Anzaldúa, 1987).

De esta forma, se aprecia en los relatos una dimensión episódica, que da cuenta de los hechos, y otra dimensión configurante, donde la trama cambia los acontecimientos en la historia. En este acto se logra la unidad de la totalidad temporal, transformando una sucesión en un todo significante, definido como tema o punto final (Ricoeur, 2007). De acuerdo con lo anterior, 
White (1992: 154) sostiene que lo configurativo produce el símbolo, "que dice más de lo que dice”, pero en la narración siempre dice lo mismo: historicidad. Por tanto, las narraciones anuncian intersubjetividades historizadas, encarnadas y resistentes, que se configuran en una agencia extremadamente reducida y cotidiana (Lugones, 2011).

En este artículo se postula que las dimensiones episódicas y configurativas refieren a una forma de dar cuenta de los saberes, lo cual permite responder a la interrogante de cómo desvelarlos. Para ello, se retoma el planteamiento de Kusch (2000), quien los denota como "un saber en signos", una semiótica que se construye de términos multívocos y de conceptos indicativos multidimensionales. Así, los tropos, los modos subjuntivos y el uso simbólico del lenguaje son los elementos con los cuales se conforma el saber como un instrumento de comunicación empírico y simbólico, al comprender que el saber es una inmanencia donde no existe ruptura ni aislamiento del ser en el saber; asociado a la experiencia y al mundo cotidiano que ha sido definido como una herramienta epistémica y política, exigiendo entender que la lucha y la decolonialidad ocurren en el campo del saber, como una oportunidad de retomar nuestras formas de habitar el mundo. Los saberes conforman una categoría que posibilita dar cuenta de lo múltiple y fragmentado de los habitares de los sujetos, donde se integra etnicidad, clase, género, sexualidad y lengua, nunca individual y construido a partir de fragmentos e hilos de diversas tramas (Anzaldúa, 1987).

En palabras de Foucault (1968), se habla de saberes sujetos que han sido descalificados, como no competentes o insuficientemente elaborados, saberes ingenuos, jerárquicamente inferiores, por debajo del nivel de conocimiento o cientificidad requerido. No obstante, su carácter en esencia local da cuenta de una especie de producción teórica autónoma, no centralizada; es decir, que no necesitarían del beneplácito de un sistema de normas comunes para afirmar su validez.

Según Santos (2010), esto obliga a poner especial atención al epistemicidio que se ha desatado en la historia de América Latina. A partir de aquí, se propone en el presente artículo un abordaje de los saberes como un consentir que nos desplazamos en una raigambre hermenéutica y fenomenológica, lo cual lleva al mundo de la vida, desde una perspectiva global y con voluntad de cohesión interna, vertebrando otros espacios, situaciones y significados (Contreras y Ramírez, 2017).

Por consiguiente, el saber, entendido de la forma como se ha ido formulando, materializa la premisa de Freire (1969), la cual intenta instalar al sujeto como un ser-saber de relaciones, que no solo está en el mundo, sino 
con el mundo; pues, el saber, como una estancia, anuncia los múltiples modos de "echar raíces", de hacer del no lugar un lugar, para desde ahí participar plenamente en la interacción social (Contreras y Ramírez, 2017). Esto lleva a plantear que desvelar saberes contribuye a la resistencia a partir de la diferencia colonial (Lugones, 2011). En una epistemología feminista, los saberes, tal como se están comprendiendo, harían referencia a concebir la experiencia como palabra de autoridad en sí misma (Smith, 2016).

En este contexto, se propone atender la vinculación entre la narración y los saberes, en la tarea de producir comprensiones respecto a la migración, en especial a la resistencia, en el mínimo sentido de agencia requerido para que la relación oprimir/resistir sea de tipo activo, a diferencia del máximo sentido de agencia impuesto al sujeto moderno (Lugones, 2008), con el fin de distanciarse de la tentación de ir construyendo la imagen de mujeres migrantes estereotipadas o victimizadas. Para ello, se ha recurrido particularmente a la dimensión configurativa de la narración, debido al proceso de transformación en una totalidad significante que anuncia saberes. ¿Qué saberes? Aquellos que advierten la testimonialidad inherente al ser, entre ellos, expresiones lingüísticas y/o tropos que actúan como protonarración, dotando de verosimilitud a la narración, además de remitir a la noción de que los seres humanos disponen de conceptos que ellos mismos han forjado, constituyéndose en sí mismos en un fenómeno existencial, el cual en cada caso es interpretado en el espacio de la comprensión pública vital (Fink, 2009).

Desde la perspectiva de Lugones (2008), los saberes que recrean una subjetividad activa, captando el sentido mínimo de agencia y permitiendo quitar los velos coloniales (Du Bois, 2001), lo cual contribuye a reconocer la especificidad de la opresión; saberes que, por su carácter, permiten rescatar la lucha emocional y sentida de habitar en formas complejas; que hospedan, a la vez, al enemigo y a nosotros mismos (Crenshaw, 2018). Saberes oscuros que se generan en experiencias violentas, pero que, no obstante, son elocuentes y de vital importancia frente a la necesidad de sobrevivir (Zipin, 2009).

En este punto, cabe destacar la originalidad del presente estudio, en el sentido de que su foco se centra en mirar la migración y los saberes que se movilizan en la experiencia, en y desde los relatos de mujeres, quienes se desempeñan como profesionales en el país de acogida, teniendo un "buen pasar" en términos económicos, escapando a la tendencia de la mayoría de las investigaciones realizadas en Chile, que atienden a las trayectorias migratorias asociadas a los puestos de trabajo, ubicados en la parte inferior de la pirámide social. Todo esto en un contexto donde la migración alcanza 
aproximadamente el 2,3\% de la población nacional (Observatorio Iberoamericano sobre Movilidad Humana, Migraciones y Desarrollo, 2016).

El objetivo de esta investigación es desvelar los saberes que despliegan seis mujeres profesionales colombianas en sus trayectorias migratorias en Chile, sobre todo en los procesos de crianza; en un contexto donde las marcas de la colonialidad se visibilizan en los lugares que las mujeres migrantes continúan ocupando y en cuyo locus de enunciación se configura la maternidad. Para la cual se deben relativizar los lugares comunes que se le impone habitar, asumiendo la maternidad como práctica en estrecha relación con el contexto cultural, social y económico donde se realiza (Bidaseca, 2015).

Para muchas mujeres migrantes, esta práctica se traduce en criar a los hijos en una sociedad constituida por estructuras de opresión, dominación racial, explotación económica y ordenamientos patriarcales. A esto se suma la ambivalencia de los planteamientos de la economía capitalista, dirigidos a deconstruir la identidad alrededor del bienestar colectivo, demandando, al mismo tiempo, que las mujeres sigan siendo seres-para-los-otros (Freixas 2015; Villenas y Moreno, 2001; Lugones, 2011), donde los procesos de enseñanza-aprendizaje entre madres e hijos se forjan en medio de tensiones y contradicciones, pero también como espacios de posibilidad. En este sentido, la acción pedagógica familiar involucra el dilema de enseñar a los hijos a encajar en los sistemas de opresión, con el fin de garantizar su supervivencia $y$, por otro lado, enseñarles a no convertirse en participantes voluntarios de su propia subordinación.

\section{Metodología}

La investigación se llevó a cabo al alero de la metodología cualitativa, con un enfoque narrativo, por considerarse lo más pertinente de acuerdo con el objetivo planteado. El diseño responde a un estudio de casos múltiples, donde el relato de cada participante se construye por medio de entrevistas que se desarrollan en diversos encuentros.

\section{Cómo se narra}

Las narraciones se construyeron por medio de tres entrevistas narrativas realizadas en los hogares de las entrevistadas, entre agosto de 2016 y julio de 2017. Con base en lo señalado por Riessman (2008), respecto a que las entrevistas son ocasiones narrativas, se puso especial atención en brindar a las participantes la oportunidad de entregar los testimonios "a su manera”. Por ello 
fueron entrevistadas por mujeres de nacionalidad colombiana, profesionales y migrantes, para asegurar, de cierta forma, la configuración de una atmósfera de interacción recíproca.

Después se llevó a cabo un análisis narrativo, donde de acuerdo con lo planteado por Cornejo et al. (2008), se privilegió en un primer momento la singularidad de cada experiencia relatada intra-caso, y en un segundo momento, una modalidad transversal inter-caso. Asimismo, se aplicaron análisis temáticos y estructurales, los cuales, como lo plantea Riessman (2008), no son excluyentes. Respecto al análisis estructural, se desarrolló considerando la propuesta de Ibáñez (1985), la cual se enfoca en la vinculación de los elementos y estructuras de verosimilitud referencial, lógica, poética y tópica, que permitió prestar atención a la manera como el relato intenta aparecer como verdadero, en el ámbito de sus relaciones con el mundo (Contreras y Ramírez, 2017).

\section{Quiénes narran}

Seis mujeres que han optado por migrar a Chile en compañía de sus hijos y residen en comunas de la capital. Estas mujeres entregan sus palabras como testimonio de su estar en el mundo. En la presente investigación se rescataron sus voces, que muy pocos han escuchado y no se contemplan para abordar el fenómeno de la migración. En la tabla ubicada en el Anexo, al final del presente artículo, se pueden observar algunos datos de las participantes (véase Tabla 1).

\section{Desarrollo}

Las narraciones que se exponen adoptan tres formas: la primera, denominada episódica, da cuenta de un relato construido por quienes entrevistan, donde se sintetiza la experiencia migratoria narrada por las participantes. La segunda expone la dimensión configurativa denominada protonarración, la cual anuncia una forma de echar raíces, que en el proceso de análisis se identifica como un saber que configura la narración de las participantes. La tercera forma corresponde al relato interpretativo elaborado por las investigadoras, en vista de que la narración no es un fin en sí misma, pues su valor en las ciencias sociales se estima por su contribución a los procesos de re-significación de las formas y decires que habitan matrices coloniales y de violencia. 


\section{Diana}

Dimensión episódica de la narración

El primer intento por migrar a Chile es un acontecimiento que difícilmente podrá ser igualado en términos de contingencias, abatimientos y pesares por Diana, una fonoaudióloga colombiana, quien llega por primera vez a Chile en 2009 sin documentos de identidad, con $\$ 500$ pesos en el bolsillo (menos de un dólar) y agobiada por un avanzado estado de meningitis aguda, que se va agravando durante el viaje. Su situación familiar, la insatisfacción profesional y las ganas de darle un nuevo rumbo a su vida la motivaron a emprender el largo viaje. La primera vez que intenta ingresar es rechazada por la autoridad migratoria, por lo cual se ve obligada a regresar a su país. Posteriormente, su esposo se traslada a Chile por trabajo, y siete meses después Diana viaja también, dejando a su hijo Daniel al cuidado de su madre. A su llegada a Chile, y para su sorpresa, descubre que su esposo tiene ya una nueva familia. Sin embargo, él le ofrece apoyo económico hasta que pueda trabajar y ser independiente. La inserción laboral en Chile no le resulta difícil, pues consigue trabajar al mes siguiente a su llegada y regulariza sus documentos.

No obstante, es discriminada por algunos compañeros de trabajo y por la directora de un establecimiento, quien arrojaba desinfectante cada vez que ella salía de su oficina. La Iglesia, su círculo cercano, la lectura y capacitación permanente han cambiado su vida. Actualmente tiene una nueva pareja sentimental. Juntos intentan permanentemente "deseducar" a su hijo; es decir, potenciar su inteligencia emocional y reorientar la educación convencional, por considerar que esta no sirve de mucho, si se trata de encontrar la libertad financiera y la felicidad verdadera. Aunque extraña a su familia en Colombia, considera que lo que ella hace en Chile es importante para todos ellos, pues más adelante podrá ofrecerles su ayuda. Diana ve a Chile como una "tierra de oportunidades".

Dimensión configurativa de la narración

Protonarración: "Me voy a esclavizar seis meses más"

Claro, o sea yo no quiero que sea empleado [refiriéndose a su hijo], le digo: no te emplees, igual ahora me salió un reemplazo de una chica que está en embarazo y yo le digo: ah, me voy a esclavizar seis meses más, solo seis, Daniel. ¿Cuándo te esclavizas?, me dijo, y yo: ya la próxima semana (risas). Y ponérselo en esos términos, porque es eso, es esclavizarse prácticamente (Diana). 
Tal como lo plantea Hinkelamnert (2017), el ser humano es un ser necesitado, al comprender que todo ser debe integrarse en el circuito natural de la vida, a partir de un proceso histórico que expresa en términos de necesidades el imperativo de integración. Esta especificidad es la que se devela en la protonarración de Diana, además de configurar submundos que abarcan el mundo entero a través de la división social del trabajo, pues al estar sometido a las relaciones mercantiles, el trabajo es concebido en abstracto (trabajar para otro), alejándose de la idea de que como seres humanos necesitados nos corresponde el trabajo y haciéndose visible los efectos en la vida. "No es vida que se vaya a encerrar a un lugar a conseguir un empleo detrás de un mueble, detrás de un escritorio, no?" (Diana)

Las relaciones mercantiles configuran mundos extremos, donde algunos vivirán y otros estarán condenados a la muerte. Frente a esta relación, mercado-no vida, Diana se resiste en y desde su narración, configurando un saber que es indispensable de recrear en sus procesos de crianza. Claramente, ella se rebela a la enajenación existente entre el trabajador y el trabajo, constituyendo una dualidad que lo aleja de su vida misma, resistiendo el automatismo del mercado. En este sentido, es posible apreciar que en la vivencia de la migración se exacerba tal mistificación y distancia entre el ser necesitado y el trabajo que le corresponde, en especial cuando las actuales fronteras entre trabajo femenino lícito y su explotación en tanto trabajadoras son imprecisas (Laite, 2017).

De este modo, podría interpretarse que este es un saber no moderno, el cual instituye prácticas ecológicas, económicas y espirituales opuestas a la lógica dicotómica, jerárquica, colonial y categorial moderna del trabajo; es decir, permite poner en alerta a sus hijos respecto a que en ciertas condiciones el trabajo es un reflejo de las relaciones de dominación, donde los estereotipos, la discriminación y el discurso del colonialismo están inscritos. Así, los prepara a no consentir voluntariamente la subordinación. De acuerdo con Lugones (2011), este saber es resistente, pero algo oscuro y colonial.

\section{Elizabeth}

\section{Dimensión episódica de la narración}

Elizabeth es una mujer nacida en una zona rural de Colombia. Inicia su proceso migratorio hace nueve años motivada principalmente por razones económicas, ya que las condiciones laborales en Colombia no eran buenas y se encontraba desempleada. Viaja sola, planificando una estadía temporal 
que se ha ido extendiendo, sin darse cuenta. En cuanto llega a Chile inicia la revalidación de su título profesional y después entra a trabajar en una escuela de lenguaje. Hace algunos años quedó embarazada y se fue a vivir con el padre de su hijo, de origen colombiano, pero meses más tarde se separó de su pareja.

Cuando Elizabeth habla de su vida y de las dificultades que ha tenido que ir superando, recuerda que en un momento, cuando ella estuvo desempleada, debió soportar los malos tratos de su pareja, por no tener un lugar a dónde ir. Cuando se menciona el tema de la discriminación, comenta que en un establecimiento educativo donde trabajó, su remuneración era inferior a lo que correspondía y además, el sostenedor la humillaba. En este sentido, lo que más le llamó la atención fue que todos se dieron cuenta de los malos tratos y nadie hizo nada. Del mismo modo, comenta que ha perdido de forma involuntaria su identidad y considera que esto se evidencia principalmente en la forma de vestir, pues debió cambiar para pasar desapercibida en una cultura diferente a la colombiana. Quiere quedarse un tiempo más, pero no pierde de vista la idea de retornar, en especial ahora que su hijo está creciendo, pues desea educarlo en su país natal.

\section{Dimensión configurativa de la narración}

\section{Protonarración: "La pelea es peleando"}

Como dicen en mi casa, "la pelea es peleando", de verdad, a mí me hicieron la guerra en un trabajo por ser colombiana y por ser fonoaudióloga y lo siento, no por eso, al contrario, más trabajaba, más hacía mis cosas, más me preparaba, más cumplía con mis pacientes, porque ese no puede ser un motivo para que te denigren, al contrario, era para demostrar que uno sí sabe, que uno sí puede, que llegó a ese puesto porque sabe, no porque se lo regalaron.

En este caso, el pelear se traduce en actuar correctamente, "más me preparaba, más cumplía”, posibilitando "andar con la frente en alto”; otro saber que compone la trama de la protonarración. Por tanto, "la pelea es peleando" y "andar con la frente en alto" son dos saberes en los cuales Elizabeth establece una relación de causalidad; esto es, si no se puede pelear (causa), no se puede tener la frente en alto (efecto). Un saber que se construye en el seno familiar y que ha conformado una manera de habitar el mundo desde la infancia, constituyendo un saber que se recrea en la trayectoria migratoria para sostener estrategias de sobrevivencia y hacer frente a prácticas discriminatorias arbitrarias. Dicha estrategia no logra despegarse de la herencia colonial y mercantil, pues la pelea que menciona Elizabeth habita en la matriz del 
esfuerzo y el mérito, donde este "incluye la confianza en uno mismo, la capacidad para el trabajo mercantilizado o para la creación (que habrá de recorrer ese camino mercantilizador), la iniciativa individual, la responsabilidad, la “inteligencia y el ingenio"” (García, 2006: 276). De este modo, asumir que "la pelea es peleando", es consentir en la lucha y responsabilidad individual.

Desde otro punto de vista, en este saber se hacen presentes los otros mundos donde ha habitado Elizabeth, brindándole la oportunidad de recordarse a ella misma; implicando una resistencia infrapolítica, al adoptar formas constituyentes (Lugones, 2008). Se trataría de un saber que, en la contradicción y multiplicidad de habitar diferentes mundos, puede ser interpretado como el anuncio de la lucha de una mujer infravalorada, que se sitúa en un habitar claramente más humano, en una oposición clásica entre luchas de conquista y liberación; recurriendo a una trama ancestral, dejando de escapar de sí misma y reencontrando el sentido del pasado, siendo el pasado ahora una constelación de valores (Fanon, 1956). Un saber donde se desliza la premisa de que los sujetos no son simplemente víctimas u oprimidos, ni solo opresores o victimarios.

Más bien, este saber y sus prácticas dan cuenta de que el sujeto negocia dentro de lo imaginario con una alteridad descolonizadora; un saber mestizo que se moviliza en enseñanzas estratégicamente ambiguas, moviéndose en los espacios intersticiales de colonialidades, patriarcados, nación y capitalismo, como espacios con posibilidad de interrupción (Villenas, 2001). Se considera que este saber configura espacios donde los hijos son subversivamente instruidos para soñar más allá de las vidas de sus madres, a ser sumisos y rebeldes de manera simultánea.

\section{Mirtha}

Dimensión episódica de la narración

Mirtha tiene 32 años, es de Colombia y de profesión contadora. Llega a Chile hace cinco años dejando a su hija al cuidado de su madre. La razón más importante para salir de su país fue que estaba pasando por una difícil situación económica. Ella inicia su viaje hacia Chile apoyada por su hermana. Menciona que fue una época difícil, pues llegó sin dinero. Una vez iniciada la revalidación de su título debe esperar un largo tiempo, por fortuna contaba con el apoyo de su hermana con quien vivía. Inicialmente trabaja en un restaurante de comida rápida y luego en una peluquería, donde se fue ganando la confianza de sus jefes, de tal manera que en ocasiones administraba el 
local. No refiere discriminación evidente hacia su persona por su condición de migrante, sino más bien por ser mujer con un jefe machista. Sin embargo, relata que su hija sí ha sufrido discriminación por el color de su piel y estatura, y teme que ella, quien solo tiene 12 años, adopte las mismas costumbres de sus compañeras, que ya fuman, pues en su país eso no se ve. Referente a la crianza de su hija afirma que continúa promoviendo sus prácticas culturales, al considerar que están basadas en los valores, las tradiciones y en lo que a ella le inculcaron desde pequeña. En relación con sus compatriotas, relata que no tiene muchos amigos colombianos, pues piensa que algunos han dañado la imagen, perjudicando a quienes trabajaban de forma honesta.

\section{Dimensión configurativa de la narración}

Protonarración: "Me he esforzado mucho para hacerme un nombre"

Donde veo colombianos trato de no involucrarme mucho, yo creo que no soy patriota en ese sentido, porque lamentablemente han dejado muy mala imagen y iyo he trabajado muy duro, muy duro aquí! y me he esforzado mucho para hacerme un nombre y como ganarme el respeto de la gente, y no quiero que de pronto por actitudes de otras personas se vaya a dañar mi esfuerzo.

"Hacerse un nombre" se concibe como un valioso elemento del patrimonio moral y social de la persona, al ser inseparable de la dignidad (Torres, 2015); además de ser la garantía de un buen actuar, cuyos resultados en su trayectoria migratoria le han significado el reconocimiento en su trabajo. "Sí, me ha ido bien, yo creo que tengo la venia de mi jefe o el dueño de la empresa que confía harto en mí, entonces es positivo ¿no?, eso es positivo”.

Un buen nombre que se gesta en el comportamiento adecuado, avalado por ser: respetuosa, responsable, colaboradora y honesta. Cualidades altamente valoradas por la sociedad que la acoge. Una sociedad que, no obstante, la vigila y sospecha de su acento, de su piel, de los colores de su vestimenta y de su cuerpo exuberante. Sabe que ser colombiana significa tener que mitigar los efectos producidos por sus compatriotas que no gozan de ese buen nombre.

El saber de hacerse un nombre se gesta en el espíritu del capitalismo, cuya base es el mérito, pues se configura en la creencia de un mercado que recompensa el esfuerzo y la inteligencia de cada individuo, transformándose en una verdadera piedra angular del funcionamiento del sistema económico neoliberal. De tal forma que las dimensiones humanas quedan reducidas a la acción individual como motor de desarrollo personal y productivo. "Hacerse un nombre" implica admitir que está mejor situado 
y es "legítima” su posición privilegiada, pues es el resultado de un "mérito"; mientras que la posición del Otro se visualiza como producto de una "culpa", de un no esfuerzo (Weber, 1973). El Otro colombiano.

Se trata de un saber que se entreteje en el legado colonial del honor y la vergüenza, y se apropia como un modo de dignidad e integridad cultural. Hacerse de un nombre es parte de una buena educación (Villenas, 2001). En consecuencia, la madre enseña a sus hijos lecciones de mérito y esfuerzo, que reflejan un fondo "moral" del saber. Un saber imprescindible en las lógicas de movilidad que enfatizan la valoración del capital cultural o los méritos individuales. Un recurso precario, pero siempre disponible para aminorar la amenaza indeseable del fracaso en su proyecto de ascenso (Arango, 2016). Finalmente, remite a interpretar este saber desde las propuestas feministas críticas al giro afectivo, que señalan que las fantasías de progreso, principalmente las de movilidad social ascendente, constituyen un afecto particular donde operan aspectos ideológicos que buscan que los sujetos se mantengan apegados a vidas que, en los hechos, no resultan en su felicidad (Macón, 2014).

\section{Mónica}

\section{Dimensión episódica de la narración}

Nacida en Barranquilla, Mónica ejercía su profesión de abogada en su país de origen. Además, estuvo casada por 17 años; no obstante, por los malos tratos de su marido decide separarse. Inicia su proceso migratorio hacia Chile hace aproximadamente dos años, cuando a los cincuenta años de edad decide migrar, debido a la deteriorada relación con su marido, además de haber recibido amenazas de muerte por temas relacionados con su trabajo. Tiene cuatro hijos varones. Sale del país con su hijo menor de 15 años, los otros tres se quedan al cuidado de su madre. Ya en el país inicia su proceso de revalidación de título y búsqueda de escuela para su hijo.

Sus primeros empleos fueron como sacristana y vendedora, hasta que pudo trabajar como abogada. Cuenta que la época más difícil fueron los primeros meses, pues además de no conseguir empleo tuvo que falsear su currículum, omitiendo su profesión y presentando solo estudios de enseñanza media para poder emplearse. Cuando se indaga sobre su vida y dificultades relacionadas con la discriminación, asegura que esta es muy fuerte en el país, sobre todo hacia la mujer; menciona que por vestirse, maquillarse y ser diferentes son fuertemente criticadas, y que los chilenos asocian estas costumbres con la prostitución. 
Respecto a la crianza de su hijo, afirma que continúa promoviendo sus prácticas culturales, al considerar que están basadas en los valores y en el respeto por el otro. Señala que en Chile se vive tranquilo en comparación con su país, por eso estará algunos años más ejerciendo su profesión de abogada. En la actualidad, tiene una oficina particular donde atiende, en especial a migrantes, y forma parte de la coordinadora nacional de migrantes, apoyando desde su profesión.

\section{Dimensión configurativa}

\section{Protonarración: "Dejar pasar, dejar hacer"}

Cuesta el tema de la disciplina, cuesta el tema de las normas, porque aquí todo es dejar pasar, dejar hacer [...] Hora de entrada, hora de salida, presentación personal, actividades para la casa, trabajos de investigación, etcétera. [...] Acá no hay disciplina en el sentido de ingreso y salida, los muchachos podía ir como quisieran en la presentación, con cabello largo, aritos en las orejas, los tatuajes, fumando... poco respeto hacia el profesor.

Al consultarle si en su hogar hay normas, explica:

Hemos dejado los principios y valores que uno trae de allá, no se tienen muy en cuenta aquí [...] entonces eso afecta un poco, porque no puede uno ejercer la autoridad de la forma como la ejercía allá, porque los hijos tienen ya otros elementos para no obedecer.

Las trayectorias migratorias implican movilizar saberes latentes, pero también re-significarlos de acuerdo con los nuevos posicionamientos que se definen en la sociedad de acogida. Esto tiene lugar en un espacio donde coexisten diversas prácticas culturales, donde es inevitable que estas se reconfiguren. Una de esas reconfiguraciones es la que se sintetiza en la protonarración "Dejar pasar, dejar hacer". Esta frase encierra un fuerte posicionamiento político-económico, pero en ámbitos más cotidianos adopta una postura práctica de no preocuparse demasiado por el curso de las cosas. En y desde el relato de Mónica, equivale a "permitir que haga"; anunciándose un saber basal que funciona como estrategia de inclusión en el país de acogida. Este saber es recreado en los procesos de crianza, que se gesta en la experiencia cotidiana y es posible ilustrar en el siguiente relato:

Mi hijo de 15 años llegaba bien presentado al colegio, cumplía con sus obligaciones, y eso fue causa de bullying en reiteradas ocasiones, por tal motivo tuve que retirarlo del establecimiento.

De esta forma, se consiente habitar en ciertos espacios en los términos impuestos; pero, adicionalmente, se intenta construir un lugar propio, 
donde se despliegan esos saberes y prácticas que se definen como necesarios. La estrategia desplegada por Mónica confirma la importancia de relevar y validar las pautas de crianza en el espacio familiar, como "un lugar" para resignificar y re-contextualizar el capital inmaterial y material, al ser el hogar un fondo de saberes.

Este saber da cuenta de una subjetividad activa, múltiple, atrapada entre las normas y prácticas de diferentes mundos. Es, por tanto, el saber de una mujer que sufre un choque cultural, anunciándose como capaz de movilizar un pensamiento divergente, caracterizado por alejarse de patrones y metas establecidas y constitutivas, acercándose hacia una perspectiva más completa, la cual incluye más que excluye. Un saber que se constituye en la angustia de no poseer ni legitimar el sentido de todas las normas y prácticas del nuevo contexto. Finalmente, este saber da cuenta de una paradoja de unión y desunión, que no solo produce un sujeto de oscuridad y uno de luz, sino también uno que cuestiona ambos mundos y les otorga nuevos significados (Anzaldúa, 1987); pero, sobre todo, indica que lo colonial invade la intimidad del hogar.

\section{Margarita}

Dimensión episódica de la narración

Margarita es odontóloga y tiene 36 años de edad. Pertenece a una familia adinerada de la ciudad de Popayán. Decide viajar a Chile, animada por unas amigas que ya residían en el país y se encontraban ejerciendo su profesión. Su principal motivación era entonces profesional y económica, pero también una forma de escapar de su familia que siempre intentaba tomar decisiones por ella. Su proceso migratorio inició hace casi 10 años. Respecto a las diferencias culturales y las estrategias para insertarse en la cultura, afirma que lo que más le impactó fue la falta de respeto hacia la diferencia de opiniones y por el tiempo del otro.

Asimismo, comenta que tuvo que cambiar aspectos como la forma de hablar, reírse, vestir y maquillarse, debido a que estas eran asociadas a la prostitución; afirma que en su interior su espíritu sigue intacto, pero ha ido modificando el exterior casi sin percibirlo, aunque lucha siempre por mantener su identidad. En cuanto a lo social, comenta que tiene amigos chilenos que son buenas personas; sin embargo, comparte más con su grupo de amigos colombianos. Hace algunos años conoció a su pareja de origen mexicano, con quien tiene dos hijos nacidos en Chile, ambos niños asisten a la escuela. Ella 
considera que los establecimientos educativos deberían destinar más tiempo a trabajar sobre la diferencia, la diversidad y los valores, para así poder vivir en comunidad. Respecto a su forma de construirse como mujer comenta que su estrategia ha sido estar dispuesta a absorber lo bueno, todo lo que le pueda ayudar para ser mejor persona, esto lo concreta buscando actividades que la llenen de experiencias satisfactorias y la hagan feliz. Otro elemento importante en su vida son sus amigos colombianos, quienes "no permiten que se apague".

\section{Dimensión configurativa}

\section{Protonarración: "Para evitarse problemas uno calla"}

Yo creo que en cierta forma uno aunque intenta conservar sus costumbres, de todas formas uno modifica de algún modo el vocabulario, la forma de expresarse, hasta los gestos, también los puede uno cambiar, aunque algo se le sale a uno también de vez en cuando y más que todo, como el aprender a callar muchas cosas con las que uno no está de acuerdo. [...] Como más vale callar.

La frase "Para evitarse problemas... uno calla" adopta un nuevo cariz cuando se gesta en una experiencia migratoria. Remite a una prudencia que despliega prácticas de reflexión permanente, respecto a los efectos que pueden producir ciertas palabras en un trayecto que se construye desde un "hacer lo correcto", para asegurar un proceso de inserción sin ser interpelada. Esta protonarración desafía a descubrir en los movimientos migratorios a los responsables "del sufrimiento silenciado que los migrantes arrastran debido a su necesidad de callar, ocultar e incluso aceptar agresiones cuando se trata de permanecer en un lugar intentando vivir y no ser expulsado o perseguido" (Tijoux, 2016: 29).

A partir de aquí, se releva la pertinencia de abordar las identidades como performativas, pues en y desde la experiencia de la migración estas son particularmente interpeladas, haciendo imposible que cada sujeto se ubique en una entidad anterior y fija. En otras palabras, la migración exige a los sujetos pensarse como provisionales, contingentes e inestables, como un siendo en lo que dice y en lo que calla. Margarita lo deja claro desde su protonarración, además de otorgarle la dimensión encarnada que posibilita construir comprensiones más humanas, asociadas a un saber que en los procesos de crianza podría perpetuar una cultura de servidumbre, la cual opera incluso en marcaciones de trabajos profesionales. Un saber que consiente en algún grado una reducción deshumanizante, como seres otros. Esto, trasladado a la perspectiva feminista, evidencia que dicho saber permite 
la persistencia del binomio en que sin la mujer migrante sirvienta, en su amplia acepción, la mujer occidental no-sierva se vería conflictuada, pues una habilita y sostiene a la otra (Cumes, 2012).

No obstante, en este "para evitarse problemas... uno calla" podemos reconocer a las "testigas fieles", quienes, al ser imaginadas y tratadas como inferiores, tienen la oportunidad de ser testigas. Testigo de todo lo que ve en sus infravalorados espacios, dando testimonio a los subalternos y a sus hijos, para en ese momento movilizar sus infrapolíticas, su subjetividad activa y corroer la matriz colonial (Lugones, 2011). Además, este saber se ubica en la trama narrativa en que se constituye, demandando comprender a las mujeres migrantes como sujetos construidos por los procesos históricos y abandonar la idea de que ellas se encuentran llamadas a reivindicar características culturales, sociales y biológicas, como algo naturalmente dado por el lugar donde habitan (Cumes, 2012).

Eli

Dimensión episódica de la narración

Eli es una mujer de 35 años de edad, de profesión fonoaudióloga, casada y madre de dos hijos, el primero de cinco años y el segundo, recién nacido. Cuando inició su proceso migratorio, hace nueve años, aún estaba soltera, pero de novia con quien ahora es su esposo. La decisión de migrar fue exclusivamente de Elizabeth, pero al ver su novio que ella viajaba a Chile decide acompañarla. Ambos inician su viaje con una motivación netamente económica. Elizabeth logra emplearse muy pronto en una escuela de lenguaje donde le hicieron un contrato de trabajo para agilizar la documentación de la visa. Declara haber contado con la fortuna de que su jefe era muy buena persona y el ambiente laboral agradable. Respecto a su identidad, señala que sin darse cuenta ha tenido que modificar algunas tradiciones culturales como su forma de vestir, de maquillarse, los colores de su ropa y la forma de hablar, para poder insertarse en la cultura chilena, pues agrega que en ocasiones se sentía muy observaba. Tras el nacimiento de sus hijos tuvo que recurrir a una sala cuna, pues ella debía continuar trabajando para responder por los gastos de la casa. Indica que hasta ahora se cuestiona el no haber tenido el suficiente tiempo para su hijo, ya que salía muy temprano a trabajar y llegaba tarde. Eli sueña con retornar a su país de origen, pues no quiere que sus hijos se críen en el ambiente chileno, alejados de sus familias, viviendo en un departamento reducido y, más aún, sin tiempo para ellos. 


\section{Dimensión configurativa}

Protonarración: "He contado con la fortuna de dar con personas que han sido buenas personas"

Contamos con la fortuna de que la señora que nos arrendaba el cuarto, [...]; por lo menos en mi caso, he contado con la fortuna de dar con personas que han sido buenas personas, buenos jefes, pues nunca yo he recibido de parte de ellos algún tipo de discriminación, o que me hayan tratado de cierta manera por el hecho de ser colombiana [...] Porque claro, afortunadamente yo tenía unos jefes que eran considerados.

Tal como se aprecia, el relato de Eli está configurado en y desde "la fortuna", como una suerte divina donde el sujeto afortunado parece tener éxito gracias a la divinidad, prosperando gracias a su impulso. "La fortuna" constituye un sistema de sentido, contribuyendo a la conformación de una particular visión del mundo. Del mismo modo, "la fortuna" se muestra como una representación religiosa que engloba al conjunto de construcciones imaginarias, mediante las cuales Eli confiere un sentido a su experiencia cotidiana. Este saber configura prácticas que, de acuerdo con Anzaldúa (1987), sacan a la luz el papel de la cultura, incluida la religión como forma de tiranía, como medio de chantaje que desde dentro/fuera se articula contra las mujeres subordinadas y racializadas para aplacar su rebeldía.

De ahí que la fortuna sea un concepto predefinido por los paradigmas dominantes, que la ven como una forma eficaz de apaciguar la insurrección. Nos referimos a una ley que las mujeres transmiten. Este concepto asegura que ellas muestren una mayor aceptación y capacidad para adaptarse al sistema de valores que insisten en su sumisión (Anzaldúa, 1987). En otras palabras, la fortuna en la lógica de la supervivencia y superación opera en la más extrema dependencia de la arbitrariedad o la buena voluntad de otros, en el marco de relaciones clientelistas y la búsqueda de reciprocidad; es decir, en ella actúan mecanismos de subvaloración y restricción del capital cultural.

\section{Limitaciones del estudio}

Entre las limitaciones de esta investigación hemos de mencionar que los resultados obtenidos entregan una visión focalizada y parcial, por lo cual no son extrapolables a otras realidades o circunstancias. 


\section{Conclusiones}

\section{Desenlace}

En la idea de que "la experiencia es saber extraer de todas las contingencias una nueva pre-comprensión” (Gadamer, 1998: 239), se asume que concebir un desenlace para la narración construida es una experiencia que se torna compleja de anunciar, si no se recurre a la familiaridad de contar una historia. Por lo tanto, recuperar el valor de la experiencia en los textos científicos es el propósito de la presente investigación.

De ahí que se narre la siguiente historia:

En una actividad de difusión de los resultados de esta investigación, una académica que con su acento nos traslada a España, admite que no tiene cercanía con las perspectivas etnográficas y que recién está aterrizando en Chile. Ella pregunta: ¿De los saberes expuestos, cuáles serían los tres más importantes? Desde esta pregunta se constata una distancia más extensa que el mar que separa ambos continentes, pero que, no obstante, le da cuerpo y voz a la relevancia de la lucha epistemológica de la localización, poniendo el acento en las pretensiones sobre la vida de la gente, en aspectos que abarcan desde un cuerpo hasta un habitar contradictorio, estructurante y estructurado (Haraway, 1995).

Hablar de jerarquizaciones obliga a seguir buscando formas de dar cuenta de estos saberes sumergidos y desvalorizados, con miras a una auténtica insurrección (Foucault, 2003); reforzando la idea de comprender la importancia de la lucha y los procesos de decolonialidad en el campo del saber, retomando las propias y contingentes formas de habitar el mundo. Por ello, preguntar por saberes más importantes que otros es seguir desperdiciando la experiencia, sin lograr reivindicar los saberes de aquellas mujeres subalternas, insertas en un supuesto universalismo. Menos aún es posible concebir la multiplicidad en la fractura del locus de enunciación de la migración y de la colonialidad del género. Entonces, no se logra persuadir de que la multiplicidad nunca se reduce ni jerarquiza (Lugones, 2011).

Otro caso: Un investigador en temas de migración pregunta: ¿Qué distingue a estos saberes de aquellos que se pueden identificar en la experiencia de otras mujeres migrantes no colombianas o no profesionales? Responder a esta interrogante condujo a la relación de lo universal y lo particular. Para ello, se retomó el planteamiento de Laclau (1996: 46), quien señala que "lo universal emerge de lo particular, no como un principio que fundamenta y explica lo particular, sino como un horizonte incompleto que sutura una 
identidad particular dislocada”. Estos y otros saberes son una "salida simbólica” a las agitaciones emocionales generadas por el desequilibrio social que implica la llegada a otra sociedad y que son, por lo menos de una manera general, comunes a todos los que viven la migración, pero que siguen ocupando un determinado papel o posición social; por lo tanto, las reacciones ideológicas a tales perturbaciones tenderían a ser similares. Sobre todo, estos saberes denuncian la inexistencia de polaridades, indicando que no existen resoluciones armónicas a la herencia que divide su ser en luz/oscuridad, madre/prostituta, víctima/victimaria; se imponen como saberes que anuncian y contienen la contradicción, haciendo de la ambivalencia algo positivo (Anzaldúa, 1987).

Finalmente, como desenlace, se considera que las narraciones presentadas en su aspecto episódico y configurativo anuncian feminismos situados, mestizos e intrusos, con lealtades divididas y desapegados de pertenencias exclusivas, que en el acto de narrar acogen la tensión y el conflicto de las peligrosas y blasfemas encrucijadas que movilizan su habitar en mundos diferentes y simultáneos; los cuales, no obstante, se encuentran comprometidos con cuestionar las geopolíticas del conocimiento colonial, que intenta imponer que algunos saben y otros no saben. En síntesis, estos relatos invitan a viajar a través de habitares y, por tanto, a apreciar la erosión del sistema capitalista-modernocolonial (Lugones, 2011).

Se concluye que en un sistema que mantiene prácticas históricas de dominación y subordinación, los saberes aportan a su deconstrucción, sobre todo cuando se analizan las cartografías migratorias de las mujeres relacionadas con los procesos de crianza, debido a que en este proceso se van configurando subjetividades activas. Especialmente, mediante la producción de lo cotidiano, de las historias que se narran, de los consejos que se entregan a los hijos, se van configurando resistencias, las cuales buscan revertir prácticas de dominación y colonización. En suma, los saberes tal y como se exponen en este artículo, aportan a las propuestas latinoamericanas para decolonizar el feminismo; además, aunque de modo incipiente, permiten revisar en el entretejido de la modernidad sistemas e ideologías como el capitalismo, patriarcado, racismo y democracia liberal.

\section{Referencias}

Alarcón, Reynaldo (1997), Orientaciones teóricas de la psicologia en América Latina, Perú: Universidad Femenina del Sagrado Corazón.

Anzaldúa, Gloria (1987), "Borderland/La Frontera", en La nueva mestiza, Estados Unidos: Aunt/Lutte. 
Arango, Luz (2016), “Género, discriminación étnico-racial y trabajo en el campo popularurbano: experiencias de mujeres y hombres negros en Bogotá", en La manzana de la discordia, núm. 2, vol. 2, Colombia: Siglo del Hombre Editores.

Baeza, Enrique (2015), “Trabajo racializado. Una reflexión a partir de datos de población indígena y testimonios de la migración y residencia mapuche”, en Revista Meridional, núm. 4, Chile: Meridional.

Bidaseca, Karina (2015), "Feminicide and the Pedagogy of Violence", en Melville, G. y Ruta, C. [eds.], Thinking the body as a basis, provocation and burden of life. Studies in intercultural and historical contexts, Alemania: De Gruyter Oldenbourg.

Contreras, Sylvia y Ramírez, Mónica (2017), “Análisis fenomenológico del tropo pasar a llevar", en Atenea, núm. 515. DOI: 10.4067/S0718-04622017000100203. Disponible en: http://www.scielo.cl/scielo.php?script=sci_arttext\&pid=S07180404622017000 100203\&lng=es\&nrm=iso [22 de septiembre de 2017].

Cornejo, Marcela et al. (2008), "La investigación con relatos de vida: Pistas y opciones del diseño metodológico", en Psykhe, vol. 17, núm. 1. Disponible en: http:// www.scielo. cl/pdf/psykhe/v17n1/art04.pdf [2 de mayo de 2017].

Crenshaw, Kimberle (2018), "Demarginalizing the intersection of race and sex: A Black feminist critique of antidiscrimination doctrine, feminist theory, and antiracist politics", en Feminist Legal Theory, Inglaterra: Routledge.

Cumes, Aura Estela (2012), "Mujeres indígenas patriarcado y colonialismo: un desafío a la segregación comprensiva de las formas de dominio", en Anuario de Hojas de Warmi, España: Universidad de Murcia.

DuBois, William Edward (2001), The education of Black people: Ten critiques, 1906-1960, Estados Unidos: NYU Press.

Fanon, Frantz (1956), "Racismo y cultura”, en Por la revolución africana, México: Fondo de Cultura Económica.

Fink, Eugen (2009), Fenómenos fundamentales de la existencia humana. Disponible en: http://www.observacionesfilosoficas.net/download/fenomenosfundamentales.pdf [1 de septiembre de 2017].

Foucault, Michel (1968), Las palabras y las cosas. Una arqueología de las ciencias humanas, Argentina: Siglo XXI.

Foucault, Michel (2003), Hay que defender la sociedad. Curso del College de France (19751976), España: Akal Ediciones.

Freire, Paulo (1969), Pedagogía del oprimido, Chile: Edición Incompleta.

Freixas, Laura (2015), El silencio de las madres y otras reflexiones sobre las mujeres en la cultura, España: Universitat Oberta de Catalunya.

Gadamer, Hans-Georg (1998), Arte y verdad de la palabra, España: Paidós.

García, Jesús (2006), La tensión entre mérito e igualdad: el mérito como factor de exclusión, España: Universitat de Valencia. Disponible en: http://www.tdx.cat/bitstream/ handle/10803/9860/civico.pdf ? sequence $=1$ [24 de abril de 2017].

Grollmus, Nicolás y Tarrés, Joan (2015), "Relatos metodológicos: difractando experiencias narrativas de investigación”, en Forum: Qualitative social research, vol. 16, núm. 2. Disponible en: http://www.qualitative-research.net/index.php/fqs/article/ view/2207/3809 [19 de julio de 2017].

Haraway, Donna (1995), Ciencia, cyborgs y mujeres. La reinvención de la naturaleza, España: Cátedra. 
Hinkelammert, Franz (2017), La vida o el capital. El grito del sujeto vivo y corporal frente a la ley del mercado, Argentina: Consejo Latinoamericano de Ciencias Sociales y Asociación Latinoamericana de Sociología.

Ibáñez, Jesús (1985), “Análisis sociológico de textos o discursos”, en Revista Internacional de Sociología, vol. 43, núm. 1, España: Instituto de Estudios Sociales Avanzados.

Kusch, Rodolfo (2000), El pensamiento indigena y popular en América, Argentina: Fundación Ross.

Laclau, Ernesto (1996), “Universalismo, particularismo y la cuestión de la identidad”, en Emancipación y diferencia, Argentina: Ariel.

Laite, Julia (2017), “Between Scylla and Charybdis: Women's Labour Migration and Sex Trafficking in the Early Twentieth Century", en International Review of Social History, vol. 62, núm. 1. DOI: 10.1017/S00208590160064X. Disponible en: https://www. cambridge.org/core/journals/international-review-of-social-history/article/divclasstitlebetween-scylla-and-charybdis-womens-labour-migration-and-sex-traffickingin-the-early-twentieth-centurydiv/ AA964CD717669E3F67F89301629B5A9E [18 de agosto de 2017].

Loebach, Peter y Korinek, Kim (2012), “Crossing borders, crossing seas: The Philippines, gender and the bounding of cumulative causation”, en International Migration, vol. 54, Canadá: Wiley. DOI: 10.1111/imig.12022.

Lugones, María (2008), “Colonialidad y género”, en Revista Tabula Rasa, núm. 9. Disponible en: http://www.revistatabularasa.org/numero-9/05lugones.pdf [02 de agosto de 2017].

Lugones, María (2011), "Hacia un feminismo descolonial", en La manzana de la discordia, núm. 6, vol. 2. Disponible en: http://www.bdigital.unal.edu.co/48447/1/ haciaelfeminismodecolonial.traducci \%C3\%B3n.pdf [25 de julio de 2017].

Macón, Cecilia (2014), “Género, afectos y política: Lauren Berlant y la irrupción de un dilema”, en Revista Debate feminista, núm. 49, México: Epiqueya.

Massey, Douglas et al. (1994), "An Evaluation of International Migration Theory: The North American Case", en Population and Development Review, vol. 20, núm. 4. DOI: 10.2307/2137660. Disponible en: http://www.jstor.org/stable/2137660 [27 de julio de 2017].

Observatorio Iberoamericano sobre Movilidad Humana, Migraciones y Desarrollo [OBIMID] (2016), La migración en Chile: breve reporte y caracterización, España: OBIMID.

Olivos, Edward y Sandoval, Gerardo (2015), "Latina/o identities, the racialization of work, and the global reserve army of labor: Becoming Latino in Postville, Iowa”, en Ethnicities, vol. 15, núm. 2, Estados Unidos: Sage. DOI: 10.1177/.

Padilla, Beatriz y Cuberos-Gallardo, Francisco (2016), "Deconstruyendo al inmigrante latinoamericano: las políticas migratorias ibéricas como tecnologías neocoloniales", en Horizontes Antropológicos, núm. 46. DOI: 10.1590/S0104-71832016000200007. Disponible en: http://www.scielo.br/pdf/ha/v22n46/0104-7183-ha-22-46-0189.pdf [5 de octubre de 2017].

Ricoeur, Paul (2001), La metáfora viva., España: Trotta.

Ricoeur, Paul (2007), Tiempo y narración I, México: Siglo XXI.

Riessman, Catherine (2008), Narrative methods for the human sciences, Estados Unidos: Sage.

Rivera-Cusicanqui, Silvia (1993), "La raíz: colonizadores y colonizados", en Violencias encubiertas en Bolivia, vol. 1, Bolivia: Ediciones Aruwiyiri. 
Santos, Boaventura (2010), Descolonizar el saber, reinventar el poder, Uruguay: Ediciones Trilce y Universidad de la República.

Sayad, Abdelmalek (2011), La doble ausencia. De las ilusiones del emigrado a los padecimientos del inmigrado, España: Anthropos.

Smith, Dorothy (2016), "El punto de vista (Standpoint) de las mujeres: conocimiento encarnado versus relaciones de dominación", en Temas de Mujeres, núm. 8, Argentina: Universidad Nacional de Tucumán.

Tijoux, María Emilia (2016), Racismo en Chile. La piel como marca de la inmigración, Chile: Editorial Universitaria.

Torres, Henry (2015), El derecho al buen nombre. Disponible en: http://www.banrepcultural.org/ blaavirtual/ayudadetareas/politica/el_derecho_al_buen_nombre [3 de octubre de 2017].

Villenas, Sofía y Moreno, Melissa (2001), "To valerse por sí misma between race, capitalism, and patriarchy: Latina mother-daughter pedagogies in North Carolina", en International Journal of Qualitative Studies in Education, vol. 14, núm. 5, Inglaterra: Routledge.

Wallerstein, Immanuel y Balibar, Etienne (1991), Raza, nación y clase, Madrid: Iepala.

Weber, Max (1973), La ética protestante y el espiritu del capitalismo, España: Península.

White, Hayden (1992), El contenido de la forma: narrativa, discurso y representación, España: Paidós.

Zipin, Lew (2009), "Dark funds of knowledge, deep funds of pedagogy: Exploring boundaries between lifeworlds and schools", en Discourse: Studies in the Cultural Politics of Education, vol. 30, núm. 3, Reino Unido: Taylor and Francis. 
Convergencia Revista de Ciencias Sociales, núm. 79, 2019, Universidad Autónoma del Estado de México

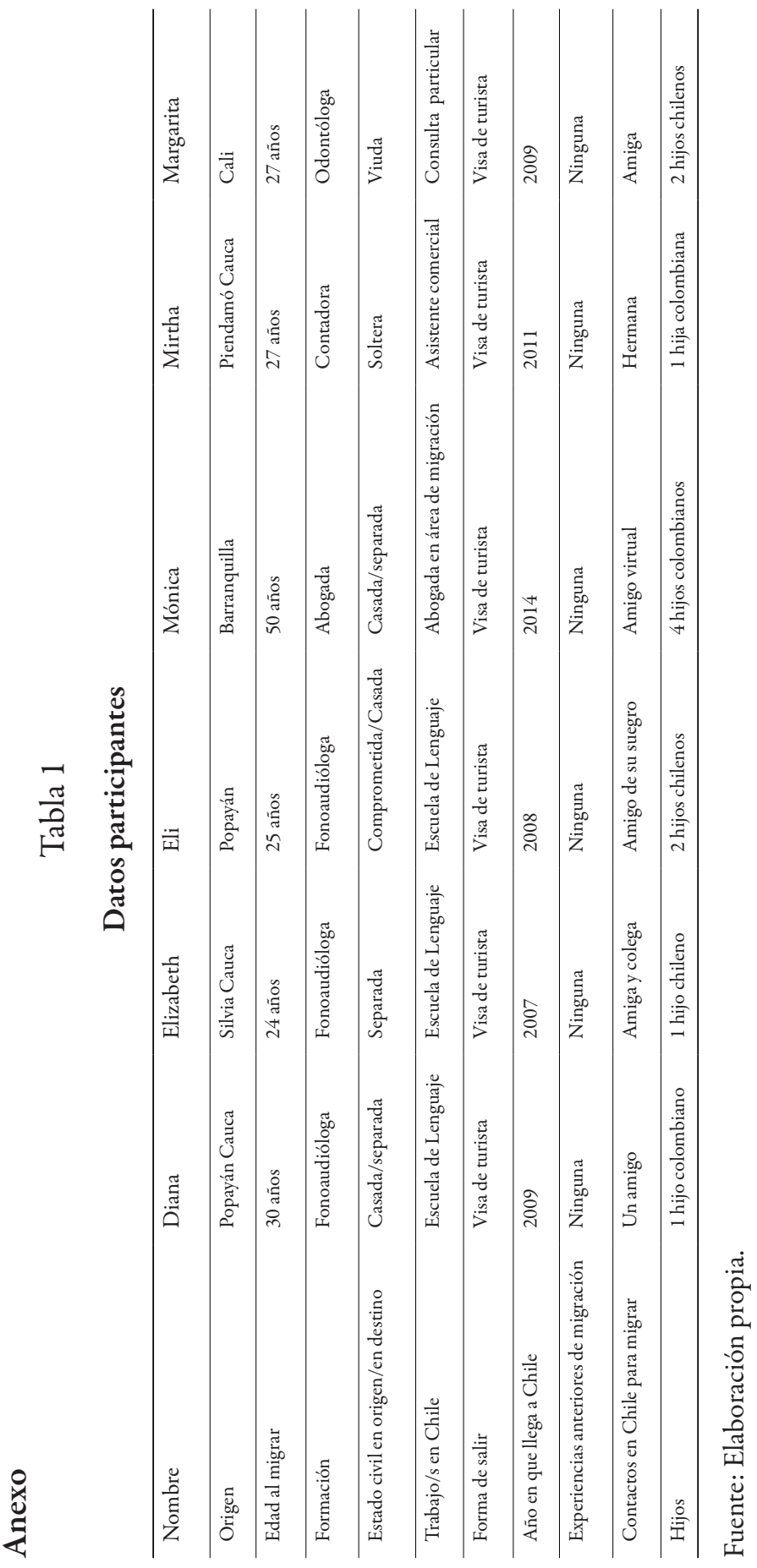


Sylvia Contreras-Salinas. Doctora en Pedagogía de la diversidad sociocultural por la Universidad Complutense de Madrid. Académica del Departamento de Educación de la Universidad de Santiago de Chile. Líneas de investigación: saberes, diversidad y educación. Publicaciones recientes: Contreras-Salinas, Sylvia (2017), “Análisis fenomenológico del tropo 'pasar a llevar”, en Revista Atenea, Chile. DOI: 10.4067/S0718-04622017000100203; Contreras-Salinas, Sylvia (2016), "Sujeción y resistencia de sujetos LGTB en la Educación Secundaria", en Revista Latinoamericana de Educación Inclusiva, Chile. DOI: 10.4067/S0718-73782016000200004; Contreras-Salinas, Sylvia (2016), "Narrativas de identidad afectivo-sexual LGTB en contextos escolares: el aparecer frente al Otro", en Estudios Pedagógicos, Chile. DOI: $10.4067 /$ S0718-07052016000100015.

Cristina Bambague-Ruiz. Magister en Educación inclusiva, Universidad Central de Chile. Pos-título en Educación Inclusiva y Diversidad, Universidad Central de Chile. Fonoaudióloga por la Universidad del Cauca, Colombia. Líneas de investigación: intervención en lenguaje, habla y audición.

Yolima Barrera-Ruiz. Magister en Educación Inclusiva, Universidad Central de Chile. Kinesióloga e Hipoterapeuta, Fundación Universitaria María Cano, Colombia. Líneas de investigación: Neurokinesiología pediátrica e Intervención en escuelas de educación especial. 